\title{
DAVID HARVEY: PARA ALÉM DE UMA GEOGRAFIA DO CAPITAL
}

O objetivo inicial de David Harvey, preservado e expandido ao longo de sua trajetória e de sua vasta obra, consistia basicamente em tentar entender a urbanização no capitalismo. Nessa direção, dedicou-se, nos anos I96o e nos primórdios dos anos I970, a estudar os desenvolvimentos históricos das principais cidades da Grã-Bretanha, da França e dos Estados Unidos, percurso sintetizado parcialmente no livro A justiça social e a cidade (I973).

Harvey atribuiu as carências dessa primeira versão a uma compreensão insuficiente da teoria marxiana. Para sanar esse déficit procurou se posicionar no debate, então aceso por conta de argumentações marcadamente contraditórias sobre o sentido da interpretação e a necessária atualização da obra de Marx. Concentrou seus esforços - numa época em que ainda ressoavam as polêmicas em torno do significado dos textos de juventude de Marx - nos livros e manuscritos posteriores a I850, um conjunto que Roman Rosdolsky denominou de "crítica da economia política".

Em Os limites do capital, publicado em I982, Harvey buscou não se afastar muito de seu interesse original. Avaliava que esse aparente desvio consistia apenas numa propedêutica indispensável à abordagem marxista do processo urbano. Tanto assim que, na Introdução descreve o livro como "um tratado sobre a teoria marxiana em geral, prestando atenção na circulação do capital nas áreas construídas e na produção das configurações espaciais" (Harvey, 2013: 36). 
De modo geral, o livro procura integrar os aspectos financeiro (temporal) e geográfico (global e espacial) sob uma teoria do sentido do movimento de acumulação do capital. Não prescinde, no entanto, de um exame acurado do papel ali desempenhado pela intervenção do Estado, concebendo esta, de certo modo, como um "momento vital na dialética e na dinâmica contraditória da acumulação do capital" (Harvey, 2013: 21).

As questões suscitadas em suas pesquisas acerca da dinâmica urbana, desdobradas na investigação dos procedimentos do mercado imobiliário e dos desenvolvimentos geográficos desiguais demandaram o esclarecimento do papel desempenhado, no interior da teoria marxiana, por fatores como capital fixo, finanças, crédito, gastos públicos etc. Desse modo, a motivação prévia de buscar fundamentos para uma explicação mais adequada da circulação do capital no mundo urbano, do modo como a renda se relaciona com os processos básicos de produção e distribuição, em suma, dos mecanismos que determinam a configuração espacial característica do capitalismo, desembocou numa reconstituição da "crítica da economia política".

Nesse afã, Os limites do capital se constituiu como uma exposição eminentemente teórica. Harvey não deixa de ressaltar, no entanto, que o livro prescinde das dimensões históricas, geográficas e políticas da obra de Marx tão somente por conta do recorte do objeto.

No decorrer do tempo, aquilo que a princípio parecia menos, revelou-se mais. O demorado mergulho no "deserto de gelo da abstração" estabeleceu um reservatório que possibilitou a Harvey, desde então, intervir com pertinácia em diversos debates políticos e teóricos. ${ }^{\mathrm{I}}$ Municiado como poucos, propôs reflexões instigantes nas sucessivas pautas desencadeadas pelas profundas modificações históricas do capitalismo nos últimos quarenta anos. Emergiram assim uma série de indagações que ele procurou, na sequência, resolver, moldando inflexões inesperadas por meio das quais, sem abandonar o solo original, sua obra ultrapassou a condição de mera geografia do capital.

Os passos de Harvey reiteram um procedimento recorrente na linhagem do marxismo. Os autores dessa vertente, desde Friedrich Engels, conduziram a tarefa de atualização do materialismo histórico, exigência inerente a um movimento que se concebe como eminentemente histórico, combinando o diagnóstico do presente histórico com uma revisitação da obra de Marx - revisão que resultou, nos casos bem-sucedidos, tanto numa interpretação original da teoria marxiana como na ampliação do escopo da doutrina. ${ }^{2}$

A ordem dos fatores é indiferente. Embora Harvey tenha começado com uma apresentação da teoria marxiana, ele próprio reconhece que sua preocupação primordial consistia em buscar respostas para os desafios impostos ao marxismo pela crise econômica que eclodiu, com uma intensidade inaudita desde i929, nos primeiros anos da década de i970. 
A utilização desse arsenal, certamente, foi um dos elementos que possibilitaram que a participação de Harvey na querela sobre o pós-modernismo lhe rendesse um reconhecimento público quase imediato, alçando-o ao panteão dos grandes teóricos do marxismo contemporâneo.

\section{A CONTROVÉRSIA SOBRE O PÓS-MODERNISMO}

Ao longo dos anos I980 a discussão acerca da pertinência do conceito de pós-modernidade passou de tópico marginal à pauta essencial do debate marxista. Essa mudança só se tornou possível, no entanto, com a superação de um paradigma. Costumeiramente, as descrições de época ensejadas pela linhagem marxista combinavam análises dos ritmos da dinâmica econômica e da conjuntura política com certa dose de "filosofia da história". A polêmica sobre a pós-modernidade, no entanto, desde seus primórdios, se caracterizou por associar a configuração do presente histórico com a discussão de tendências estéticas e culturais.

Um dos primeiros marxistas a tratar a questão da pós-modernidade nesses termos foi Jürgen Habermas, numa série de intervenções - cujo marco inicial foi o discurso por ocasião do recebimento do prêmio Theodor Adorno, em Frankfurt, em setembro de I980 - que adquiriram ressonância mundial. O artigo, denominado "Modernidade versus pós-modernidade", ressalta tanto a dimensão sociológica como a estética.

O neoconservadorismo norte-americano, que tem em Daniel Bell um de seus expoentes, segundo Habermas, não pode ser compreendido adequadamente quando se desconsidera que se trata, sobretudo, de um antimodernismo cultural, uma espécie de esquizofrenia que louva o progresso econômico, mas rejeita suas consequências no campo da cultura e do comportamento. $\mathrm{O}$ fulcro do artigo, no entanto, consiste na apresentação de sua posição acerca da discussão estética então vigente, abordando temas como a autonomia da arte, o legado das vanguardas e o declínio do modernismo.

Habermas retomou e desenvolveu essa análise de forma breve no opúsculo A nova intransparência, e de maneira mais extensa no livro 0 discurso filosófico da modernidade, ambos de i 985 . Sua defesa do projeto moderno como um conjunto de potencialidades ainda não efetivadas, como algo inacabado, viga mestra de seu combate simultâneo ao antimoderno e ao pós-modernismo, não deixa de configurar, no entanto, um desvio em relação à avaliação prevalecente no marxismo. Inspirados no Manifesto comunista, os principais nomes dessa linhagem procuraram destacar o caráter contraditório do capitalismo - a combinação de aspectos positivos, como a urbanização e a industrialização, com traços negativos: a exploração, a reificação etc. Por meio dessa "dialética da modernidade", o marxismo se colocou simultaneamente como crítico e defensor da sociedade moderna. 
$\mathrm{Na}$ tentativa de delimitar a configuração histórica de seu tempo, Habermas mira simultaneamente três âmbitos distintos: o neoconservadorismo anglo-saxão; François Lyotard e o pós-estruturalismo francês; o debate estético nas artes plásticas e na arquitetura. Ao restringir o debate sobre o pós-modernismo a esses aspectos, Habermas evita arriscar uma explicação dos processos econômicos e sociais que promoveram a mudança cultural - indagação que ele próprio reclama não ter sido atendida por Daniel Bell. Atrelado à apreciação da modernidade como um projeto inacabado, Habermas se exime, portanto, da tarefa de delinear uma teoria histórica do capitalismo.

Mediada em grande parte pelos textos de Jürgen Habermas, a continuação desse debate transformou a cultura numa espécie de campo de prova da consistência do conceito de pós-modernismo. O enfoque estritamente sociológico, predominante na querela acerca da possível emergência de uma sociedade pós-industrial, cedeu lugar a uma controvérsia estética que - como mostrou Perry Anderson em As origens da pós-modernidade - já emergira desde a primeira metade do século $\mathrm{XX}$.

Fredric Jameson foi um dos primeiros, entre os marxistas, a discordar da rejeição, capitaneada por Habermas, do conceito de pós-modernismo. Ele começou a escrever sobre o assunto em I982, mas sua posição só adquiriu ressonância com a publicação, em I984, na New Left Review, do artigo "A lógica cultural do capitalismo tardio", que veio a se tornar o primeiro capítulo de seu livro Pós-modernismo (I99I).

Esse artigo compreende o termo pós-modernismo como a designação de um signo cultural próprio de um novo estágio da história do capitalismo. Com esse movimento, Jameson instaurou uma inflexão de esquerda num conceito e numa discussão cujas origens remetiam à manutenção da ordem existente. ${ }^{3}$ O uso do termo lhe afigura como irrecusável não só pelas contingências intelectuais norte-americanas, mas, principalmente, por considerá-lo como a descrição mais adequada de uma situação em que a modernização, totalmente implantada, não se defronta mais com obstáculos (leiam-se natureza e formas sociais pré-capitalistas) a serem superados. Pós-modernismo, segundo Jameson, nomeia, discrepando da tese de uma "modernização incompleta", uma terceira etapa, o capitalismo multinacional, sucessor do capitalismo monopolista (a fase do imperialismo) e do primevo capitalismo de mercado.

Assim, a transformação cultural é concebida como signo e sintoma de uma metamorfose no interior do próprio modo de produção capitalista. Além de recortar esses três momentos da história do capitalismo, Jameson se propõe a identificar os principais aspectos da terceira fase do capitalismo, em especial a dimensão cultural. ${ }^{4}$ Para estabelecer a topografia desse mundo no qual a própria palavra modernização é prescindível, já que nele tudo é, por definição, "moderno", Jameson adota como régua e compasso a determinação da lógica específica da cultura "pós-moderna". 
Seu primeiro passo consiste na delimitação dos traços recorrentes na produção, mas também nas teorias explicativas, do pós-modernismo, no período que se estende desde a institucionalização acadêmica do modernismo, em meados dos anos I960, até os anos I990. Salienta, em especial, a canibalização aleatória de estilos do passado, a predominância estilística de pastiches (distintos das paródias valorizadas pelo modernismo); a criação de um hiperespaço muito além da capacidade humana de se localizar, seja pela percepção ou mesmo pela cognição, no meio circundante; a transferência da ênfase no objeto pela primazia da representação; a lógica espacial do simulacro etc.

O pós-modernismo, segundo Jameson, produziu uma alteração profunda das experiências da vida cotidiana, afetando substancialmente a percepção e a vivência psíquica dos indivíduos. Modificações que derivam não apenas do esmaecimento do sentido histórico, com a substituição do predomínio da categoria tempo pela noção de espaço, mas, sobretudo, da transmutação, no bojo do processo de reificação das coisas em imagens.

O estabelecimento de conexões, a descoberta de afinidades entre fenômenos e esferas aparentemente distintas e autônomas - um anátema para as teorias da modernidade assentadas em Max Weber -, legitima-se, no pós-modernismo jamesoniano, pela dissolução explosiva da autonomia da esfera cultural, descrita por ele como uma prodigiosa expansão da cultura até o ponto em que tudo em nossa vida social - do valor econômico e do poder do Estado às práticas individuais e à estrutura da psiquê - deve ser melhor descrito como um fenômeno cultural.

O êxito de Jameson em tornar a discussão sobre a pós-modernidade aceitável e até mesmo decisiva no interior do marxismo deriva, em parte, do alcance de dois procedimentos que ele manejou com maestria. Primeiro, Jameson forneceu um quadro teórico - ao mesmo tempo abrangente e refinado - da estética pós-moderna, valendo-se de sua familiaridade com a teoria estética do marxismo ocidental, objeto de seu livro Marxismo e forma. Além disso, atribuiu à "cultura" pós-moderna uma delimitação mais ampla. Determinou-a, na trilha aberta por Raymond Williams, como uma "sensibilidade" ou "sentimento", isto é, como um conjunto de práticas, motivações da ação e de atribuição de sentido ao mundo e à existência.

Assim, Jameson não só marcou de forma nítida a ruptura entre a estética da modernidade e a da pós-modernidade (ancorada na primazia da imagem sobre os objetos, sustentada pela disseminação da televisão e do computador pessoal), mas também estabeleceu a cultura como terreno comum, o que tornou possível o confronto e a comparação entre as diversas teorias da modernidade. Na sua argumentação em favor da ruptura entre nossa época e o passado imediato, ressalta tópicos como a transmutação da reificação - o fetiche não deriva mais apenas da autonomia ilusória das coisas, mas, principalmente, das imagens; a mudança na estrutura da subjetividade - a individualidade não se cons- 
titui mais por meio de uma relação temporal que incorpora passado, presente e futuro, mas encontra-se submersa numa "presentificação" em que o tempo é substituído por relações espaciais; e a hegemonia a-histórica do aqui e agora.

O calcanhar de Aquiles da exposição de Jameson sobre o pós-modernismo localiza-se em sua tentativa de explicar essa mudança histórica a partir de uma teoria apresentada por Ernest Mandel em I972.5 Não só pelo fato de 0 capitalismo tardio ter sido escrito antes do desabrochar pleno das teorias e das práticas que moldaram a cultura pós-moderna, mas também porque o próprio Mandel data a eclosão dessa terceira fase do capitalismo em I945. ${ }^{6}$

Com a publicação, em I989, de Condição pós-moderna, David Harvey se tornou uma das vozes mais influentes nesse debate. Seu livro associa a mudança nas práticas culturais, subjacentes ao termo pós-modernismo, com alterações político-econômicas que teriam se iniciado no final da década de I960, tornando-se mais visíveis a partir de 1973.

Harvey se mostra bastante ciente da conexão necessária entre teoria sociológica e estética, como fica evidente na passagem seguinte, quase uma carta programa:

Há muito a aprender com a teoria estética sobre o modo como diferentes formas de espacialização inibem ou facilitam processos de mudança social. Inversamente, há muito a aprender com a teoria social acerca do fluxo e da mudança com os quais a teoria estética tem de se haver. Contrastando essas duas correntes de pensamento, talvez possamos melhor compreender os modos pelos quais a mudança político-econômica contribui para as práticas culturais (Harvey, I992: 192).

Dito em termos mais específicos, Harvey relaciona as novas experiências frente ao tempo e ao espaço (o engendramento de uma nova sensibilidade ou o sentimento qualificado como "pós-moderno") com a emergência de modalidades diferentes, mais flexíveis, de acumulação do capital, o início de um novo ciclo de "compressão do tempo-espaço na organização do capitalismo". Isso não significa, no entanto, que ele endosse a tese do surgimento de uma sociedade pós-capitalista ou mesmo pós-industrial, ao contrário.

Um dos pontos fortes de Condição pós-moderna assenta-se na atenção que dedica à experiência urbana nas grandes cidades - um tópico essencial das teorias sobre a modernidade. Harvey identifica no pós-modernismo uma alteração profunda das experiências da vida cotidiana, que afetam substancialmente a própria percepção e a vivência psíquica dos indivíduos. Ele, de certo modo, atualiza as considerações dos principais teóricos da modernidade, em especial de Charles Baudelaire e Georg Simmel, nas quais se ressalta o processo de abstração patente nos novos estilos de vida, na experiência do choque, na atitude de reserva, na disseminação da relação monetária etc. Para Harvey, o pós-modernismo não significa apenas uma mudança no estatuto da produção cultural, sinaliza também uma modificação no próprio modo de vida com a generalização de novas práticas, experiências e formas de vida. 
Condição pós-moderna mescla a teoria marxista das crises econômicas, esmiuçadas por Harvey em Os limites do capital, com a teoria histórica da "escola da regulação". Em seu esforço para compreender a crise da década de I970, ele testou as principais explicações prevalecentes no interior da linhagem marxista, identificando problemas em cada uma delas.

Harvey considera que a tese do "esmagamento do lucro" - aquela que "encara que a organização da força de trabalho e a escassez de mão de obra reduzem a taxa de acumulação até o ponto de crise da classe capitalista e, por extensão do sistema capitalista como um todo" (Harvey, 20I3: 28) - explica parcialmente a situação, mas não consegue fornecer respostas convincentes para alguns dos pontos decisivos da crise.

Ele rejeita também a tese de que a crise seria provocada por "subconsumo" ou, numa terminologia não-marxista, por deficiências na demanda efetiva. Essa teoria, apresentada inicialmente por Rosa Luxemburgo, defendida e desenvolvida por adeptos do marxismo keynesiano, também lhe pareceu incapaz de explicar os fenômenos específicos da crise dos anos I970.

Por fim, Harvey discorda da teoria da "queda tendencial da taxa de lucro", que consistiria num resultado não previsto pelos capitalistas em seu denodo para introduzir na indústria inovações tecnológicas e reduzir a força de trabalho. Afirma que, "o próprio Marx anexou tantas advertências, condicionalidades e circunstâncias mitigadoras a essa teoria que é difícil sustentá-la como uma teoria geral da crise" (Harvey, 2013: 28).

A teoria delineada por Harvey procura, no entanto, incorporar dimensões dessas três correntes. Em sua busca de uma explicação mais abrangente considera que as crises econômicas do capitalismo derivam, em última instância, de sua tendência congênita à superacumulação de capitais. Nas palavras de Harvey: "as crises surgem quando as quantidades sempre crescentes de mais-valia que os capitalistas produzem não podem ser absorvidas lucrativamente" (Harvey, 2013: 28).

Para explicar o pós-modernismo, Harvey recorre ainda ao arsenal teórico da "escola da regulação", em particular, à sua famosa distinção entre "regime de acumulação" e o "modo de regulação" social e política que lhe é associado.7 Nesse diapasão, Harvey identifica no pós-modernismo uma ruptura com o modelo de desenvolvimento capitalista prevalecente desde I945. A partir da recessão de I973, a forma de acumulação predominante, o fordismo, foi minada pela crescente competição internacional e pela combinação de baixas taxas de lucros corporativos e de um processo inflacionário em aceleração. A soma desses fatores desencadeou uma crise de superacumulação.

A resposta da classe capitalista e dos governos dos países centrais a essa situação desdobrou um novo regime de acumulação. Nesse regime, denominado "flexível" por Harvey, o capital retomou sua margem de manobra e seu controle sobre o mercado de trabalho. Sua principal estratégia foi a "precariza- 
ção" das relações trabalhistas, com o estabelecimento de contratos temporários e a incorporação de força de trabalho imigrante.

Contribuíram para tanto outros fatores como a transposição - em busca de custos reduzidos - de unidades fabris para outros países ou regiões. A produção de mercadorias também foi revolucionada por processos just in time, pela prioridade dada aos lotes de encomendas etc. A principal transformação, no entanto, ocorreu nos mercados financeiros com a desregulamentação das transações em moedas (câmbio), crédito e investimentos. Esse novo regime de acumulação forneceu o solo para a cultura pós-moderna, para uma nova sensibilidade moldada pela desmaterialização do dinheiro, pelo teor efêmero da referência monetária, pela instabilidade econômica.

Uma generalização, sustentada por Harvey, consiste na tese segundo a qual as dimensões do espaço e do tempo estão sujeitas à persistente pressão da circulação e da acumulação do capital, "culminando (em especial durante as crises de superacumulação) em surtos desconcertantes e destruidores de compressão do tempo-espaço" (Harvey, I992: 293).

A crise de superacumulação iniciada no final dos anos I96o e intensificada ao longo da década de i 970 comprovaria, de certo modo, essa tese:

A experiência do tempo e do espaço se transformou, a confiança na associação entre juízos científicos e morais ruiu, a estética triunfou sobre a ética como foco primário de preocupação intelectual e social, as imagens dominaram as narrativas, a efemeridade e a fragmentação assumiram precedência sobre verdades eternas e sobre a política unificada e as explicações deixaram o âmbito de fundamentos materiais e político-econômicos e passaram para a consideração de práticas políticas e culturais autônomas (Harvey, I992: 293).

Apesar de seus inegáveis avanços, Condição pós-moderna ainda se encontra, em larga medida, presa aos esquemas conceituais forjados por Jürgen Habermas e Fredric Jameson. Mesmo a maior novidade do livro - a percepção de que se trata de uma mudança estrutural (ou de fase) do capitalismo - foi apreendida por intermédio de um diálogo com a obra de Jameson.

A reconstituição do período anterior, conceitualizado como "fordismo" - retomando o termo criado por Antonio Gramsci e as formulações da escola francesa da regulação - possibilitou a Harvey, no entanto, expor, sob o rótulo de "acumulação flexível", uma teoria própria sobre a crise e o pós-modernismo. Nela, descreve transformações decisivas no mercado de trabalho, nas formas e métodos de organização da produção e, sobretudo, na esfera financeira, no mercado de capitais e crédito.

Entretanto, apesar do esforço de Harvey para determinar com mais precisão do que Habermas e Jameson as causas econômicas, políticas e sociais da mudança cultural, só em sua obra posterior ele logrou desenvolver de forma plena e consistente uma teoria da acumulação capitalista. A partir dela, a distinção entre modernidade e pós-modernidade apresenta-se como não mais que a emergência de uma nova fase, ainda aberta, da história do capitalismo. 


\section{O DEBATE SOBRE O IMPERIALISMO}

Pouco mais de uma década após a publicação de Condição pós-moderna, em 2003, Harvey reformula seu diagnóstico do presente histórico. Procura entender, então, a nova ordem engendrada pela reação do Estado norte-americano aos atentados de I I de setembro de 200 , em especial as invasões sucessivas do Afeganistão e do Iraque.

Esses desdobramentos causaram perplexidade geral. Afinal, a disposição de ocupar tais países não estaria na contramão de uma política cuja hegemonia se firmara ao longo do século XX graças ao discurso e à prática em favor da autonomia nacional? Além disso, como entender a legitimidade obtida pelo governo Bush - uma singular coalizão de militaristas, neoconservadores e cristãos fundamentalistas, acusada de fraude eleitoral -, confirmada com sua escolha para exercer um segundo mandato?

As mudanças na ação externa e no cenário interno suscitaram a onda de explicações que colocou na boca de liberais e conservadores um termo que a esquerda utiliza há muito para caracterizar o Estado norte-americano: imperialismo. A ocupação neocolonial de territórios, seu denodo em determinar os rumos do capitalismo, o estado de guerra permanente (4I\% dos gastos do governo são destinados a atividades militares) e até mesmo o revezamento de poucas famílias no comando da nação, tudo isso apontava para o ressurgimento de um poder imperial.

Essa inusitada convergência disseminou e banalizou ao extremo a palavra "imperialismo". Quando se debruçou sobre o tema, David Harvey, para qualificar o debate, procurou restabelecer as determinações conceituais e históricas da teoria marxista do imperialismo. Mas, paradoxalmente, a atualidade de $O$ novo imperialismo reporta-se menos às análises de conjuntura - em geral brilhantes e muitas vezes proféticas -, do que ao arcabouço teórico que o livro desenvolve.

Ao contrário do que se crê, a discussão sobre o imperialismo não é episódica no corpus marxista, resquício da "era dos impérios" e do leninismo. Quando bem dimensionada, ocupa um lugar central na compreensão teórica e histórica do capitalismo. Se Marx, por um lado, caracteriza a dinâmica desse modo de produção como o desdobramento da acumulação de capitais (numa lógica estritamente econômica), por outro lado, em um capítulo crucial de 0 capital ("A assim chamada acumulação primitiva") mapeia, uma a uma, as práticas extraeconômicas que favorecem a acumulação capitalista.

O debate polarizou-se entre os que consideram a "acumulação primitiva" como mera etapa necessária à emergência do capitalismo, e os que a situam como momento estrutural de seu dinamismo histórico. A questão, no fundo, remete às relações entre economia e política, um dos muitos pontos que Marx apenas esboçou e não teve tempo de desenvolver em sua obra.

Harvey é partidário decidido da segunda alternativa. O novo imperialismo busca mostrar que o processo de "acumulação interminável de capital", que con- 
figura histórica e geograficamente o capitalismo, combina, de forma contraditória, a lógica econômica, os processos moleculares de acumulação e as estratégias políticas, diplomáticas e militares - que denomina "acumulação por espoliação", renomeando o arsenal de práticas que Marx chamava de acumulação primitiva.

A predecessora mais ilustre dessa posição foi Rosa Luxemburgo. Harvey compartilha com ela a tese de que a acumulação capitalista não prescinde de alguma espécie de ambiente externo. Discorda, no entanto, que esse "outro" seja sempre uma forma de produção pré-capitalista. O próprio capitalismo, em sua geografia e história, pode produzir esse "exterior", como no caso do desemprego em massa que amplia o exército industrial de reserva.

Ele tampouco concorda que a teoria de Rosa Luxemburgo segundo a qual a sucessão de crises que perpassa o capitalismo seria explicável pelo "subconsumo". Para Harvey, as crises advêm da dificuldade em absorver de forma lucrativa os excedentes de capital e são, portanto, "crises de sobreacumulação". Sua resolução acarreta tanto a desvalorização de ativos e a destruição de regiões como configura uma nova paisagem espaço-temporal para acomodar a perpétua acumulação de capital e, sua companheira inseparável, a acumulação interminável de poder.

Harvey também não despreza os ensinamentos de Lênin sobre o imperialismo, em especial a denúncia da assimetria entre Estados no interior de um sistema global de acumulação de capital. Mas em vez de descrever o imperialismo como uma fase "derradeira" do capitalismo prefere vê-lo, na fórmula de Hannah Arendt, como "o primeiro estágio do domínio político da burguesia". A partir dessa premissa reconstitui, com alguns deslocamentos decisivos, a hipótese de uma sucessão de Estados hegemônicos desenvolvida por Giovanni Arrighi em $O$ longo século XX.

Entre I870 e I 945 imperialismos rivais assentados no nacionalismo e no racismo conduziram as nações europeias a uma série de crises e guerras. Esse processo resultou na incontestável hegemonia norte-americana após I945. Esta se firma dissimulando seu domínio sob a capa de um universalismo abstrato: a defesa das classes proprietárias de todo o mundo em sua luta contra o comunismo. A partir de I973, o modelo de acumulação altera-se completamente com a guinada política que visa restaurar e reconstituir o poder da classe capitalista, a "contrarrevolução neoliberal", consubstancializada com a criação de um sistema monetário desmaterializado.

Nesses três períodos convivem, com pesos diferenciados, a acumulação molecular de capital e a acumulação por espoliação. Esta última vigorou no período I870-I945 e voltou a prevalecer a partir de I973, após o interregno dos "trinta anos dourados". A face imperialista do capitalismo torna-se ostensiva nos momentos em que predomina o acúmulo por espoliação, mas nunca deixa de atuar, sobretudo porque também deriva, de forma complexa, da reprodução expandida do capital. 
Essa teoria possibilitou a David Harvey - em O novo imperialismo e nos seus livros seguintes, em especial, em $O$ neoliberalismo: história e implicações e em $O$ enigma do capital e as crises do capitalismo - explicar de forma convincente os principais fenômenos político-econômicos dos últimos 35 anos, apresentando a financeirização, a globalização e a política neoliberal como estratégias da "acumulação por espoliação".

O predomínio atual da "acumulação por espoliação" manifesta-se na vida política por meio da cisão dos movimentos antiglobalização, divididos entre a esquerda socialista - cuja ênfase na reprodução ampliada coloca como central a luta anticapitalista -, e os novos movimentos sociais que tendem a assumir formas difusas, fragmentárias e avessas ao controle do aparelho de Estado, posto que lutam prioritariamente contra as múltiplas formas de espoliação.

Recebido em I3/oI/20I4 | Aprovado em 28/03/2014

Ricardo Musse é mestre em Filosofia pela Universidade Federal do Rio Grande do Sul (UFRGS), doutor em Filosofia e livre-docente em ciências sociais pela Universidade de São Paulo (USP). Professor associado do Departamento de Sociologia da USP, suas pesquisas versam sobre teoria sociológica e sociologia histórica do marxismo. Organizou os livros Capítulos do marxismo ocidental (I998) e Émile Durkheim: Fato social e divisão do trabalho (2007). 


\section{NOTAS}

I A expressão "deserto de gelo da abstração" é de Walter Benjamin, como lembra Adorno no Prefácio da Dialética negativa (Adorno, 2009: 7).

2 Sobre o papel de Engels na determinação dos procedimentos típicos da tradição marxista, ver Musse (2000).

3 Como mostrou com propriedade Perry Anderson em As origens da pós-modernidade.

4 Jameson segue a tripartição, detalhada apenas no que tange aos fatores econômicos, de Ernest Mandel em O capitalismo tardio.

5 Debilidade apontada já em I99I por Mike Davis (Davis, I993) e retomada por Perry Anderson em As origens da pós-modernidade.

6 Jameson procurou, nos escritos posteriores ao livro Pós-modernismo, corrigir essa incoerência, caracterizando esse terceiro período da história do capitalismo como o da hegemonia norte-americana - retomando a periodização de Giovanni Arrighi em O longo século XX, mas também promovendo uma espécie de simbiose entre as teorias de Mandel e de Arrighi.

7 Para uma apresentação desses conceitos, ver Harvey (I992: I I7).

\section{REFERÊNCIAS BIBLIOGRÁFICAS}

Adorno, Theodor. (2009). Dialética negativa. Rio de Janeiro: Zahar.

Anderson, Perry. (I999). As origens da pós-modernidade. Rio de Janeiro: Zahar.

Arendt, Hannah. (I989) Origens do totalitarismo. São Paulo: Companhia das Letras.

Arrighi, Giovanni. (I996). O longo século XX. Rio de Janeiro/ São Paulo: Contraponto/Ed. Unesp.

Baudelaire, Charles. (2010). O pintor da vida moderna. Belo Horizonte: Autêntica.

Bell, Daniel (I980). O fim da ideologia. Brasília: Ed. UnB.

Bell, Daniel. (1977). O advento da sociedade industrial. São Paulo: Cultrix. 
Davis, Mike. (I993). O renascimento urbano e o espírito do pós-modernismo. In: Kaplan, Ann E. (org.). O mal-estar no pós-modernismo. Rio de Janeiro: Zahar, p. I06-I I6.

Gramsci, Antonio. (2008). Americanismo e fordismo. São Paulo: Hedra.

Habermas, Jürgen. (2000). O discurso filosófico da modernidade. São Paulo: Martins Fontes.

Habermas, Jürgen. (I987). Arquitetura moderna e pós-moderna. Novos Estudos Cebrap, I8, p. I I5-I 24.

Habermas, Jürgen. (I987). A nova intransparência. Novos Estudos Cebrap, I8, p. I03-II4.

Habermas, Jürgen. (1983). Modernidade versus pós-modernidade. Arte em Revista, 7, p. 86-9I.

Harvey, David. (2013). Os limites do capital. São Paulo: Boitempo.

Harvey, David. (20 I I). O enigma do capital e as crises do capitalismo. São Paulo: Boitempo.

Harvey, David. (2008). O neoliberalismo: história e implicações. São Paulo: Loyola.

Harvey, David. (2004). O novo imperialismo. São Paulo: Loyola. Harvey, David. (I992). Condição pós-moderna: Uma pesquisa sobre as origens da mudança cultural. São Paulo: Loyola.

Harvey, David. (I980). A justiça social e a cidade. São Paulo: Hucitec.

Jameson, Fredric. (2006). A virada cultural: Reflexões sobre o pós-moderno. Rio de Janeiro: Civilização Brasileira.

Jameson, Fredric. (I996). Pós-modernismo: A lógica cultural do capitalismo tardio. São Paulo: Ática.

Jameson, Fredric. (I985). Marxismo e forma. São Paulo: Hucitec. Lênin, Vladimir I. (2008). O imperialismo. Fase superior do capitalismo. São Paulo: Centauro.

Luxemburgo, Rosa. (I976). A acumulação do capital. Estudo sobre a interpretação econômica do imperialismo. Rio de Janeiro: Zahar.

Mandel, Ernest. (1982). O capitalismo tardio. São Paulo: Abril Cultural.

Marx, Karl. (2013). O capital. Crítica da economia política. São Paulo: Boitempo. 
Marx, Karl. (20Io). Manifesto do Partido Comunista. São Paulo: Hedra.

Musse, Ricardo. (2000). O primeiro marxista. In: Boito, Armando \& Toledo, Caio Navarro et al. (orgs.). A obra teórica de Marx. São Paulo: Xamã/Ed. Unicamp, p. 8I-89.

Rosdolsky, Roman. (200I). Genêse e estrutura de O capital. Rio de Janeiro: Contraponto.

Simmel, Georg. (2013). As grandes cidades e a vida do espírito. In: Botelho, André (org.) Essencial sociologia. São Paulo: Penguin/Companhia das Letras, p. 31 I-329.

Wood, Ellen Meiksins (org.). (I999). Em defesa da história: Marxismo e pós-modernismo. Rio de Janeiro: Zahar. 
Palavras-chave

David Harvey; Pós-modernismo;

Imperialismo; Marxismo contemporâneo; Teoria marxista.

Keywords

David Harvey;

Post-modernity;

Imperialism;

Contemporary Marxism;

Marxist theory.

\section{DAVID HARVEY: PARA ALÉM DE UMA GEOGRAFIA DO CAPITAL}

\section{Resumo}

Em Os limites do capital, David Harvey atualiza e interpreta a obra de Karl Marx por meio de uma espécie de reconstituição da "crítica da economia política". Suas intervenções em diversos debates políticos e teóricos posteriores foram muitas vezes municiadas por esse trabalho. Sua participação na querela sobre o pós-modernismo, dialogando com Jürgen Habermas e Fredric Jameson, rendeu-lhe um reconhecimento público que não cessou de crescer desde então. Pouco mais de uma década após a publicação de Condição pós-moderna, Harvey reformulou seu diagnóstico do presente histórico. Em $O$ novo imperialismo debruça-se sobre a nova ordem engendrada pela reação do Estado norte-americano aos atentados de I I de setembro de 200 I. Para qualificar o debate, procurou reestabelecer as determinações conceituais e históricas da teoria marxista do imperialismo.

\section{DAVID HARVEY: BEYOND A \\ GEOGRAPHY OF THE CAPITAL}

Abstract

In Limits to capital, David Harvey updates and interprets the work of Karl Marx through a type of reconstitution of the criticism of political economy. His later interventions in a series of political and theoretical debates were often fed by this work. His participation in the dispute about the post-modernity in conversation with Jürgen Habermas and Fredric Jameson gave him growing public acknowledgement since then. About a decade after his publication of The condition of post-modernity, Harvey reshaped his diagnose of the historical present. In The new imperialism, he focuses on the new order postulated by the North-American State's reaction to the attacks of September I I th of 200 . To qualify the debate, he made an effort to reestablish the conceptual and the historical determinations of the Marxist theory of the Imperialism. 